\title{
ASSESSMENT OF ANTIBACTERIAL EFFECT OF SALVIA OFFICINALIS MODIFIED GLASS IONOMER CEMENT: AN IN VITRO STUDY
}

\author{
Rasha Mohamed Hatem Hanafy* and Mariam Mohsen Aly*
}

\begin{abstract}
Background: Salvia officinalis (S. officinalis) has been vastly used in medicine as it possesses anticaries, antiplaque, anti-inflammatory, antibacterial, antifungal, antiviral, astringent, antioxidant effects.

Aim: This study was executed to estimate the antibacterial effect of glass ionomer cement (GIC) containing S. officinalis on Streptococcus mutans (S. mutans) as main etiological factor of dental caries process.

Methods: A total number of 12 specimens were assigned into 2 equal groups: Group 1(Control group) where conventional powder and liquid Fuji IX GIC was used and Group 2 (Test group) where the S. officinalis extract was prepared and added to the GIC liquid at $0.5 \%$ weight concentration level. Six disk-shaped specimens, with diameter $10 \mathrm{~mm}$ and thickness $2 \mathrm{~mm}$, were constructed for each group then tested, in vitro, against strains of S. mutans. Diameter of inhibition zone was recorded after 24 and $48 \mathrm{~h}$.
\end{abstract}

Results: During the study period, the mean diameter of the inhibition zones was high in the test group in contrast to the control group, with high statistically significant difference.

Conclusions: Glass ionomer cement with S. officinalis extract has direct inhibitory effect towards S. mutans.

KEYWORDS: Antibacterial, Dental caries, GIC, S. mutans, S. officinalis

\section{INTRODUCTION}

Dental caries is a major public health problem that is costly to treat and impacts on the quality of life at all ages. Established on the microbial nature of dental caries, its treatment necessitates chemical control along with the traditional mechanical means of caries control ${ }^{1}$.
Glass-ionomer cement (GIC), is the first introduced fluoride-releasing material in an aqueous environment. It is a tooth-coloured, acid-based material that can be utilized as base, liner, direct restorative material and also in atraumatic restorative technique (ART) which is especially valuable for children and patients with dental anxiety or learning difficulties ${ }^{2}$.

\footnotetext{
* Lecturer of Pediatric Dentistry and Dental public health, Faculty of Dentistry, Cairo University, Egypt.
} 
To improve the anti-caries ability of GIC, many modifications such as incorporation of antibacterial agents like chlorhexidine hydrochloride, cetrimide, benzalkonium Chloride, and cetylpyridinium chloride are done to attain a material with direct antimicrobial effect that provides antibacterial seal to decrease postoperative sensitivity and recurrent caries and also to improve health of the pulp and periodontal tissue ${ }^{3,4}$.

Nowadays, herbal extracts, with potential antimicrobial effect, have gained great attention to be incorporated into oral care products and dental materials providing effective, safe and economical substitutional materials for treatment of dental caries ${ }^{5}$.

Salvia officinalis (S. officinalis), named Sage, is a perennial evergreen plant native to Mediterranean zone and cultivated in Iran. It has wooden stalks, grayish leaves and blue-purple flowers ${ }^{5,6} \cdot S$. officinalis extract has antioxidant, antibacterial, anticandidal, antiplaque, analgesic and anti-inflammatory properties. Sage tea is a worthy agent to control fever, sore throat, inflammatory oral lesions and gingivitis. The essential oil of S. officinalis consists of alpha- and beta-thujone, borneol, camphor, and cineole ${ }^{5-7}$.

Kermanshah et al ${ }^{8}$ confirmed the cariostatic action of $S$. officinalis extract through a great inhibitory effect on caries-producing oral microflora. Many studies stated the inhibitory influence of $S$. officinalis extract on Candida albicans and Porphyromonas gingivalis ${ }^{5}$. The adequacy of $S$. officinalis in lowering the numbers of Streptococcus mutans (S. mutans) colonies in bacterial plaque has been proved by Beheshti-Rouy et al ${ }^{9}$.

Therefore, the present study was done to assess any possible inhibitory action of S. officinalis modified GIC on $S$. mutans as a main etiological factor of dental caries.

\section{MATERIALS \& METHODS}

\section{Study design:}

The study design was in vitro

\section{Sample size:}

According to Shahriari et al ${ }^{10}$ a total number of 12 specimens (6 in each group) was calculated using $G^{*}$ power Program (Düsseldorf, Germany) version 3. 1. 9.4 and equation $\frac{2 \mathrm{p} \times \mathrm{q}\left(\mathrm{z}_{\alpha}+\mathrm{z}_{\beta}\right)^{2}}{\alpha^{2}}$, assuming a power of $95 \%$ and alpha $=0.05$.

\section{Methods:}

According to Shahriari et $\boldsymbol{a l}^{10}$ fifty grams of high-quality $S$. officinalis was purchased from the Experimental Plants Station, Faculty of Pharmacy, Cairo University. Leaves of the plant were chopped, cut into small pieces, filtered through a mesh, then soaked in $1500 \mathrm{ml}$ of solvent (50\% water, 50\% ethanol [96\%]) in a shaker apparatus (Jenway 1000 Hotplate/Stirrer,UK) at $90 \mathrm{rpm}$ for $48 \mathrm{~h}$. The solution was passed through a strainer and then transferred to a rotary evaporator apparatus, Rotavap, (Eyela OSB-2100, Tokyo Rikakikai Co., LTD., Japan) to separate the solvent from the purified extract. The procedure was done by a pharmacology professor, Faculty of Pharmacy, Cairo University.

The study sample was sorted into 2 equal groups:

Group 1 (Control group): included 6 specimens of conventional powder and liquid Fuji IX GIC (GC Corporation, Tokyo, Japan).

Group 2 (Experimental group): included 6 specimens prepared by adding S. officinalis extract to the liquid part of Fuji IX GIC (GC Corporations, Tokyo, Japan) at $0.5 \%$ weight concentration level, according to Kermanshah et al $^{8}$.

The liquid and powder were mixed, according to manufacturer's instructions, using a sterile spatula and then inserted into a custom made Teflon mold with diameter $10 \mathrm{~mm}$ and thickness $2 \mathrm{~mm}$ and left to set at room temperature. 
Stock culture of S. mutans (EMCC1815) was acquired from the Microbiology Laboratory, Faculty of Medicine, Cairo University and cells were cultured freshly from frozen stock on brain-heart infusion broth (HIMEDIA Laboratories, Mumbai, India) for $24 \mathrm{~h}$ at $37^{\circ} \mathrm{C}$ in a $10 \% \mathrm{CO}_{2}$ incubator. The inoculum was obtained according to De Castilho et $\boldsymbol{a l}{ }^{11}$. Then a base layer containing $15 \mathrm{ml}$ of BHI agar blended with $300 \mathrm{ml}$ of S. mutans inoculum was obtained and placed in every sterilized Petri dish $(15 \mathrm{~mm} \times 90 \mathrm{~mm})^{11}$.

The set specimens were put on a BHI agar plate inoculated with bacterial strain and left at $37^{\circ} \mathrm{C}$ for 24 and 48 h. By a digital caliper, inhibition zones were measured in millimeters at the two outermost points.

\section{Statistical analysis:}

For the two groups, diameter of zones of inhibition after 24 and $48 \mathrm{~h}$ incubation period were reported as mean \pm standard deviation. The difference in antibacterial properties between groups at the same time point was evaluated using the student'sttest. Significant level was set at $\mathrm{P}<0.05$. Statistical analysis was completed using a commercially available software program SPSS version 21 (Chicago, IL, USA).

\section{RESULTS}

According to student'st-test, the mean diameter of the inhibition zone for S. mutans, after $24 \mathrm{~h}$, in the experimental group was higher $(11.67 \mathrm{~mm})$ than

TABLE (1): Mean diameter of the inhibition zone in (mm) for Streptococcus mutans after 24 hours

\begin{tabular}{|c|c|c|c|}
\hline Groups & Mean & SD & P-value \\
\hline $\begin{array}{c}\text { Control group } \\
\text { (G.I) }\end{array}$ & Zero & zero & \\
\cline { 1 - 3 } $\begin{array}{c}\text { Experimental group } \\
\text { (G.I + S. officinalis) }\end{array}$ & 11.6666667 & 1.86189867 & $2.1302 \mathrm{E}-05$ \\
\hline
\end{tabular}

that in the control group (zero) with high statistically significant difference $(\mathrm{P}<0.05)$. After $48 \mathrm{~h}$, the mean diameter of the inhibition zone was enhanced in both groups (18.17 $\mathrm{mm}$ in experimental group and $8.17 \mathrm{~mm}$ in the control group) with high statistically significant difference between the two groups $(\mathrm{P}<0.05)$, as shown in table $(1,2)$, figure $(1,2)$.

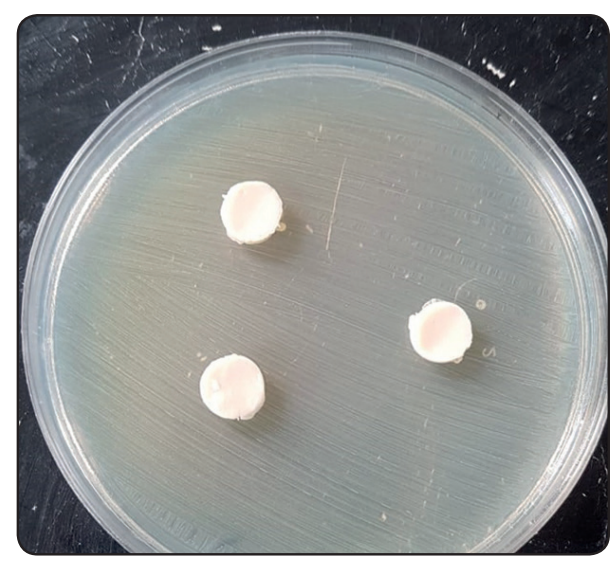

Fig. (1): Zones of bacterial growth inhibition around specimens in control group

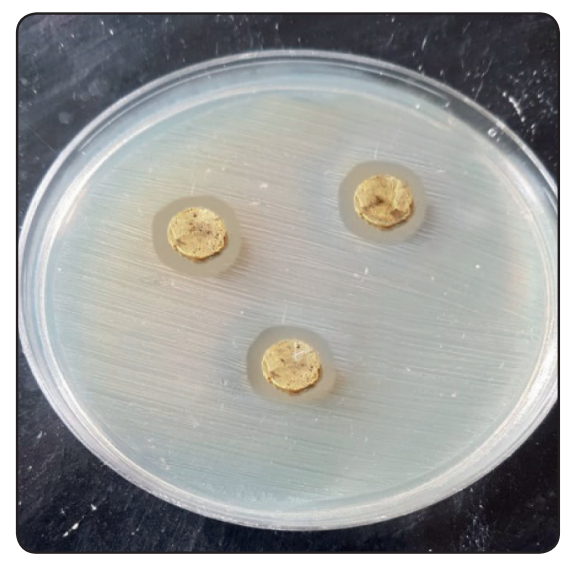

Fig. (2): Zones of bacterial growth inhibition around specimens in experimental group

TABLE (2): Mean diameter of the inhibition zone in (mm) for Streptococcus mutans after 48 hours

\begin{tabular}{|c|c|c|c|}
\hline Groups & Mean & SD & P- value \\
\hline $\begin{array}{c}\text { Control group } \\
\text { (G.I) }\end{array}$ & 8.166666667 & 1.169045194 & \\
\cline { 1 - 3 } $\begin{array}{c}\text { Experimental group } \\
\text { (G.I + S. officinalis) }\end{array}$ & 18.16666667 & 2.228601953 & \\
\hline
\end{tabular}




\section{DISCUSSION}

A distinctive benefit of this study is the utilization of safe and effective herbal extract as an alternative to chemical agents to provide a modified GIC with strong antibacterial effect ${ }^{10}$.

Fuji IX GIC was used as the control in the present study, since it is the gold standard in high strength posterior restorations. It possesses good adhesion to the tooth, good mechanical strength and anticariogenic potential. However, the anticariogenic potential of GIC is not sufficient, although it releases fluorine but not in a constant level ${ }^{12,13}$.

Procedures applied in treatment of carious lesion don't eradicate all the bacteria from the cavity. During the cavity preparation, complete removal of decalcified dentine may cause exposure of pulp. It has been confirmed that demineralized dentine can be left to protect the pulp from becoming exposed providing that the capping material has antibacterial potential against cariogenic bacteria ${ }^{14}$.

Streptococcus mutans bacterial strain was utilized for this study because of its impact as an initiator of the pathological process of dental caries. Also, the antibacterial properties of the S. officinalis show a wide variability, established on the sensitivity of microorganisms. Gram-positive S. mutans have a greater vulnerability to Salvia essential oil in contrast to other bacterial type which resulted from the morphological structure and chemical composition of their membrane ${ }^{9,15}$.

Growth of the S. mutans was assessed using the broth-dilution method with a liquid culture medium as it resembles the oral environment and GIC is a solid material which is hard to be soluble in a solid culture medium such as the agar diffusion test ${ }^{16}$.

According to the findings of the current study, conventional GIC (Group I) did not cause bacterial inhibition after 24 hours. These results were in accordance with Vermeersch et al and Yesilyurt et $a^{17,18}$ whereas the growth of S. mutans was only inhibited the second day of the study (after $48 \mathrm{~h}$ ) which agreed with the findings of $\boldsymbol{E} \boldsymbol{u c z a j - C e p o w i c z}$ et $\boldsymbol{a l}{ }^{14}$. The antibacterial influence of control specimens may be associated with release of fluoride and zinc ions into an aqueous medium, which may inhibit the growth of S. mutans. However, the release of these ions from GIC is controlled by numerous factors such as material preparation, powder/liquid ratio, handling time and temperature ${ }^{12}$.

Salvia officinalis was added to GIC at a concentration of 0.5 weight $\%$ as this is the minimal inhibitory concentration with minimal bacterial assays that can be used without decreasing the compressive strength of the set specimen ${ }^{8,10}$ also, it was proved that the addition of antimicrobials into GIC decreases its compressive strength and there is an inverse relation between the concentration of the added antimicrobials and the compressive strength of the set material ${ }^{12,18,19,20}$.

There was a high statistically significant difference of the mean inhibition zone diameter in the experimental group in contrast to the control group. This result was complementary to the findings of Shahriari et al ${ }^{10}$. This can be due to the presence of essential oils with volatile monoterpenoid as their main ingredients are described to be potent antibacterial. Essential oils can suppress microorganisms by making cell membrane more permeable leading to leakage of cell contents and ultimately cell death ${ }^{9}$.

\section{CONCLUSIONS}

At $0.5 \%$ weight concentration level, GI containing S. officinalis has a great antibacterial effect against S. mutans compared to conventional GIC.

\section{Conflict of interest and Source of Funding}

This article is original and free of conflict of interests. No funds were taken from any institution or company. 


\section{REFERENCES}

1. Hook ER, Owen OJ, Bellis CA, Holder JA, O'Sullivan DJ, Barbour ME. Development of a novel antimicrobial-releasing glass ionomer cement functionalized with chlorhexidine hexametaphosphate nanoparticles. J Nanobiotechnology. 2014;12(1). doi:10.1186/1477-3155-12-3

2. McCabe JF, Yan Z, Al Naimi OT, Mahmoud G, Rolland SL. Smart materials in dentistry - Future prospects. Dent Mater J. 2009;28(1):37-43. doi:10.4012/dmj.28.37

3. Yengopal V, Harnekar SY, Patel N, Siegfried N. Dental fillings for the treatment of caries in the primary dentition. Cochrane Database Syst Rev. 2016;2016(10). doi:10.1002/14651858.CD004483.pub3

4. Deepalakshmi M, Poorni S, Miglani R, Rajamani I, Ramachandran S. Evaluation of the antibacterial and physical properties of glass ionomer cements containing chlorhexidine and cetrimide: An in-vitro study. Indian J Dent Res. 2010;21(4):552. doi:10.4103/0970-9290.74217

5. Sookto T, Srithavaj T, Thaweboon S, Thaweboon B, Shrestha B. In vitro effects of Salvia officinalis L. essential oil on Candida albicans. Asian Pac J Trop Biomed. 2013;3(5):376-380. doi:10.1016/S2221-1691(13)60080-5

6. Thangavelu L, Narayanan N. Salvia officinalis in dentistry. Dent Hypotheses. 2015;6(1):27. doi:10.4103/21558213.150870

7. Smullen J, Finney M, Storey DM, Foster HA. Prevention of artificial dental plaque formation in vitro by plant extracts. J Appl Microbiol. 2012;113(4):964-973. doi:10.1111/j.1365-2672.2012.05380.x

8. Kermanshah H, Kamangar S, Arami S, et al. Antibacterial activity of hydroalcoholic extract of Salvia officinalis and Achillea millefolium against cariogenic microorganisms: an in vitro investigation. J Islam Dent Assoc Iran. 2009;21(3):215-220.

9. Beheshti-Rouy M, Azarsina M, Rezaie-Soufi L, Alikhani MY, Roshanaie G, Komaki S. The antibacterial effect of sage extract (Salvia officinalis) mouthwash against Streptococcus mutans in dental plaque: A randomized clinical trial. Iran J Microbiol. 2015;7(3):173-177.

10. Shahriari S, Barekatain M, Shahtalebi MA, Farhad SZ. Evaluation of Preventive Antibacterial Properties of a Glass-Ionomer Cement Containing Purified Powder of Salvia officinalis: An In vitro Study. Int J Prev Med. 2017;8:1-5. doi:10.4103/ijpvm.IJPVM
11. De Castilho ARF, Duque C, Negrini TDC, et al. Mechanical and biological characterization of resin-modified glassionomer cement containing doxycycline hyclate. Arch Oral Biol. 2012;57(2):131-138. doi:10.1016/j.archoralbio.2011.08.009

12. Mittal S, Soni H, Sharma D, Mittal K, Pathania V, Sharma S. Comparative evaluation of the antibacterial and physical properties of conventional glass ionomer cement containing chlorhexidine and antibiotics. J Int Soc Prev Community Dent. 2015;5(4):268. doi:10.4103/2231-0762.161754

13. Hafshejani TM, Zamanian A, Venugopal JR, et al. Antibacterial glass-ionomer cement restorative materials: A critical review on the current status of extended release formulations. J Control Release. 2017;262(July):317-328. doi:10.1016/j.jconrel.2017.07.041

14. Łuczaj-Cepowicz E, Marczuk-Kolada G, Zalewska A, Pawińska M, Leszczyńska K. Antibacterial activity of selected glass ionomer cements. Postepy Hig Med Dosw. 2014;68(January):23-28. doi:10.5604/17322693.1086069

15. Hegde N, Attavar S, Hegde M,Priya G. Antibacterial activity of dental restorative material: An in vitro study. J Conserv Dent. 2018;21(1):42-46. doi:10.4103/JCD.JCD_2_17

16. Hatunoğlu E, Ö Ztü Rkb F, Bilenler T, Aksakalli S, Ş Imşeke N. Antibacterial and mechanical properties of propolis added to glass ionomer cement. Angle Orthod. 2014;84(2):368-373. doi:10.2319/020413-101.1

17. Vermeersch G, Leloup G, Delmée M, Vreven J. Antibacterial activity of glass-ionomer cements, compomers and resin composites: Relationship between acidity and material setting phase. J Oral Rehabil. 2005;32(5):368-374. doi:10.1111/j.1365-2842.2004.01300.x

18. Yesilyurt C, Er K, Tasdemir T, Buruk K, Celik D. Antibacterial activity and physical properties of glass-ionomer cements containing antibiotics. Oper Dent. 2009;34(1):1823. doi: $10.2341 / 08-30$

19. Deepalakshmi M, Poorni S, Miglani R, Rajamani I, Ramachandran S. Evaluation of the antibacterial and physical properties of glass ionomer cements containing chlorhexidine and cetrimide: An in-vitro study. Indian J Dent Res. 2010;21(4):552-556. doi:10.4103/0970-9290.74217

20. Türkün LŞ, Türkün M, Ertuğrul F, Ateş M, Brugger S. Long-term antibacterial effects and physical properties of a chlorhexidine-containing glass ionomer cement. J Esthet Restor Dent. 2008;20(1):29-44. doi:10.1111/j.17088240.2008.00146.x 